\title{
A lupane-triterpene isolated from Combretum leprosum Mart. fruit extracts that interferes with the intracellular development of Leishmania (L.) amazonensis in vitro
}

Carolina Bioni Garcia Teles ${ }^{1}$, Leandro Soares Moreira-Dill ${ }^{2}$, Alexandre de Almeida Silva ${ }^{3,4}$, Valdir Alves Facundo ${ }^{5}$ Walter F. de Azevedo $\mathrm{Jr}^{6}$, Luiz Hildebrando Pereira da Silva ${ }^{7}$, Maria Cristina M. Motta ${ }^{8}$, Rodrigo Guerino Stábeli ${ }^{2}$ and Izaltina Silva-Jardim ${ }^{9^{*}}$

\begin{abstract}
Background: 3beta,6beta,16beta-trihydroxylup-20(29)-ene is a lupane triterpene isolated from Combretum leprosum fruit. The lupane group has been extensively used in studies on anticancer effects; however, its possible activity against protozoa parasites is yet poorly known. The high toxicity of the compounds currently used in leishmaniasis chemotherapy stimulates the investigation of new molecules and drug targets for antileishmanial therapy.

Methods: The activity of 3beta,6beta,16beta-trihydroxylup-20(29)-ene was evaluated against Leishmania (L.) amazonensis by determining the cytotoxicity of the compound on murine peritoneal macrophages, as well as its effects on parasite survival inside host cells. To evaluate the effect of this compound on intracellular amastigotes, cultures of infected macrophages were treated for 24,48 and $96 \mathrm{~h}$ and the percentage of infected macrophages and the number of intracellular parasites was scored using light microscopy.
\end{abstract}

Results: Lupane showed significant activity against the intracellular amastigotes of L. (L.) amazonensis. The treatment with $109 \mu \mathrm{M}$ for $96 \mathrm{~h}$ reduced in $80 \%$ the survival index of parasites in BALB/c peritoneal macrophages. At this concentration, the triterpene caused no cytotoxic effects against mouse peritoneal macrophages. Ultrastructural analyses of $L$. (L.) amazonensis intracellular amastigotes showed that lupane induced some morphological changes in parasites, such as cytosolic vacuolization, lipid body formation and mitochondrial swelling. Bioinformatic analyses through molecular docking suggest that this lupane has high-affinity binding with DNA topoisomerase.

Conclusion: Taken together, our results have showed that the lupane triterpene from C. leprosum interferes with L. (L.) amazonensis amastigote replication and survival inside vertebrate host cells and bioinformatics analyses strongly indicate that this molecule may be a potential inhibitor of topoisomerase IB. Moreover, this study opens major prospects for the development of novel chemotherapeutic agents with leishmanicidal activity.

Keywords: Lupane, Leishmania (L.) amazonensis, Combretum leprosum, Amastigotes, Macrophages, Antileishmanial activity

\footnotetext{
* Correspondence: isjcavalli@uesc.br

${ }^{9}$ Department of Biological Sciences, Universidade Estadual de Santa Cruz (UESC), Ilheús, Bahia, Brazil

Full list of author information is available at the end of the article
} 


\section{Background}

Leishmaniasis is a neglected disease caused by several protozoan species of the genus Leishmania, an intracellular parasite that infect cells of the mononuclear phagocyte system. These protozoan parasites cause a number of important human diseases, including cutaneous, mucocutaneous and visceral leishmaniasis. The parasites are transmitted by sandflies of the genera Phlebotomus (old World) and Lutzomyia (New World) by inoculation of infective metacyclic promastigote forms during the blood meal. These infective metacyclic forms are internalized by host macrophages and differentiate into amastigote forms that are able to proliferate within the phagolysosomes of mammalian macrophages, thus being responsible for the maintenance and propagation of the infection [1].

The first-line compounds for the treatment of Leishmaniasis consists of pentavalent antimonials, sodium stibogluconate and meglumine antimoniate. The second line of drugs includes pentamidine and amphotericin $\mathrm{B}$ (also formulated as liposomes). Most of these drugs present high toxicity, several side effects, and require long-term management, complicating the conclusion of treatment. Discovered in the mid-1980s, miltefosine is orally active antileishmanial drug, approved in India in 2002 for the therapy of leishmaniasis; but its efficacy on the treatment of American cutaneous leishmaniasis has been shown to be variable depending on the causative species, moreover this drug is associated with therapeutic complications [2, 3].

Plant extracts have been traditionally used in the treatment of protozoan diseases; in addition, a number of alternative compounds with antileishmanial activity have been described, including chalcones, alkaloids, triterpenes, acetogenins [4-9]. Despite of the activity of several compounds in experimental murine leishmaniasis models, the development of a single drug or formulation has been hindered by factors such as visceral and cutaneous sites of infection, intrinsic variation of the Leishmania species known to infect humans, and, finally, cytotoxicity [10].

Combretum leprosum Mart., a member of the family Combretaceae, contains many compounds, such as triterpenes, flavonoids, stilbenes, phenantrenes, lignans, alkaloids $[11,12]$. In a phytochemical study of C. leprosum roots and leaves, Facundo et al. [11] have isolated arjunolic and mollic acids and $3 \beta, 6 \beta, 16 \beta$-trihydroxylup20(29)-ene, and found out that the arjunolic acid has potent anti-inflammatory, anti-nociceptive and anticholinesterasic properties [12, 13]. Previous studies from our laboratory have revealed that $3 \beta, 6 \beta, 16 \beta$-triidroxilup-20(29)-ene obtained from C. leprosum fruit extracts exhibited anti-leishmanial activity against $L$. (L.) amazonensis promastigotes, with an $\mathrm{IC}_{50}$ of $3.3 \mu \mathrm{g} / \mathrm{mL}$ [14]. L. (L.) amazonensis is a species transmitted mainly in the Amazon region and causes diffuse cutaneous leishmaniasis (DCL) [15]. This species can be associated with localized and benign cutaneous lesions and can also cause mucocutaneous leishmaniasis [16]. Diffuse cutaneous leishmaniasis (DCL) is a form of cutaneous leishmaniasis that begins as localized and non-ulcerated papules or nodules that then spread to several parts of the body [15-17]. Although rare, DCL is a disease that does not respond to treatments in satisfactory manner [18].

There is an urgent need of new, effective and safe drugs for a better control of leishmaniasis. Therefore, new targets need to be set in order to pursue the development of a newer generation of anti-protozoan drugs, and amongst potential molecular targets, DNA topoisomerases warrant special attention. DNA topoisomerases IB are ubiquitous enzymes responsible for relaxing superhelical tension in DNA by forming a transient covalent nick in one strand of the DNA duplex [19]. DNA topoisomerase inhibitors represent a main class of anticancer drugs with an increasing number of compounds which are nowadays in clinical use. These enzymes have been also proposed as potential targets for the development of anti-protozoan drugs, such as pathogenic trypanosomatids, including Leishmania spp. [20-22]. In addition, the significant differences in homology between leishmania DNA topoisomerase IB and the human form provide a new lead in the study of the structural determinants that can be targeted [21].

The present study investigated the effects of $3 \beta, 6 \beta, 16 \beta-$ triidroxilup-20(29)-ene on the development of $L$. (L.) amazonensis amastigotes within peritoneal mouse macrophages. Furthermore, the potential affinity between leishmania DNA topoisomerase IB and $3 \beta, 6 \beta, 16 \beta$-triidroxilup-20(29)-ene was also studied using bioinformatics molecular docking analyses.

\section{Methods \\ Plant material}

Fruits of Combretum leprosum Mart. were collected in Viçosa, Ceará State, Brazil, whereas the plant species were identified by Dr. Afrânio Fernandes (Federal University of Ceará, Fortaleza). A voucher specimen was deposited in the Herbarium Prisco Bezerra of the Biology Department, Federal University of Ceará, Brazil, as number 12446. As previously described, the $3 \beta, 6 \beta, 16 \beta$-triidroxilup-20(29)ene (Fig. 1) was obtained by liquid chromatography over silica gel [11].

\section{Mice and parasites}

Female BALB/c mice aged eight to ten weeks were obtained from the breeding stock of Research Institute for Tropical Diseases - IPEPATRO, Porto Velho, RO, Brazil. Promastigotes of Leishmania (Leishmania) amazonensis PH8 strain (IFLA/BR/67/PH8) were axenically cultured 


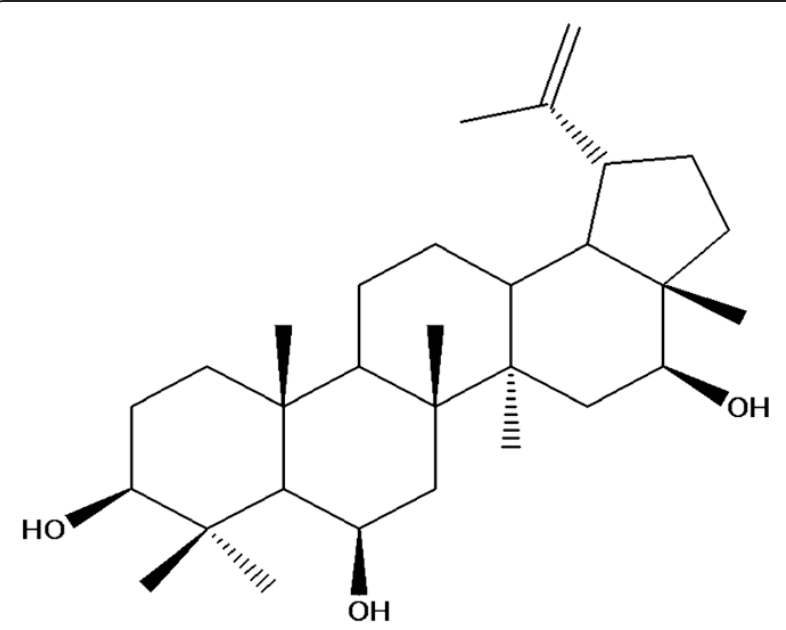

Fig. 1 Chemical structure of a natural Lupane $[3 \beta, 6 \beta, 16 \beta$-triidroxilup20(29)-ene] isolated from Combretum leprosum fruits

at $23{ }^{\circ} \mathrm{C}$ in RPMI 1640, supplemented with $10 \%$ heatinactivated fetal bovine serum (FBS), $20 \mathrm{mM}$ Hepes (N2-hydroxyetrylpiperazine-N'-2-ethanesulfonic acid), and $50 \mu \mathrm{g} / \mathrm{mL}$ of gentamycin. On the 5 th day of culture (stationary phase of growth), promastigotes were harvested and washed with RPMI by centrifugation at $1000 \times \mathrm{g}$ for 15 min. Parasite pellets were then resuspended in culture medium and used for infection of peritoneal macrophages in vitro.

\section{Toxicity on macrophages}

With the purpose of evaluating the cytotoxicity of lupane against host cells, thyoglicholate-elicited peritoneal macrophages were incubated at different concentrations $(6,5-218 \mu \mathrm{M})$ of triterpene for $24 \mathrm{~h}, 48 \mathrm{~h}$ and $96 \mathrm{~h}$, at $37{ }^{\circ} \mathrm{C}$, under an atmosphere of $5 \% \mathrm{CO}_{2}$. The samples were dissolved in ethanol. Up to $1 \%(\mathrm{v} / \mathrm{v})$, ethanol had no effect on macrophage viability and parasite growth. The viability of macrophages was determined using a CellTiter 96 Aqueous Non-Radioactive cell proliferation assay (Promega), following the manufacturer's instructions. Three independent experiments were performed in duplicate.

\section{Macrophage infection and parasite survival}

The effects of $C$. leprosum lupane on parasite replication and survival in host macrophages were evaluated by plating BALB/c thyoglycholate-elicited peritoneal macrophages into coverslips placed into 24-well culture plates and infecting them with $L$. (L.) amazonensis promastigotes at a ratio of $10: 1$ for $18 \mathrm{~h}$ at $34{ }^{\circ} \mathrm{C}$ in an atmosphere of $5 \% \mathrm{CO}_{2}$. Free parasites were removed by washing the macrophages thoroughly before adding the drugs. The infected cultures were treated with $109 \mu \mathrm{M}$ lupane. A control for the solvent used to dissolve lupane (ethanol) was also included. The cultures were incubated at $34{ }^{\circ} \mathrm{C}, 5 \% \mathrm{CO}_{2}$, and analyzed at 24,48 and $96 \mathrm{~h}$ posttreatment [23]. Infected macrophages incubated without drugs were used as control, whereas Glucantime ${ }^{\oplus}$ was used as a control drug at 546,5 $\mu \mathrm{M}$. In order to estimate the survival index, the coverslips were stained with May Grünwald-Giemsa [24] and 100 macrophages were scored by light microscopy, either as infected or non-infected. Likewise, these preparations were assessed for the number of parasites inside the macrophages. The survival index was determined by multiplying the number of infected cells by the mean number of amastigotes per cell. The results were used to establish a proportion in relation to the control and hence express the result as a percentage.

\section{Transmission electron microscopy}

Control and treated infected-macrophages were washed with Phosphate Buffer Saline (PBS) and fixed with $2.5 \%$ glutaraldehyde in $0.1 \mathrm{M}$ cacodilate buffer $(\mathrm{pH}$ 7.2). These cells were detached by gently scraping immediately after the addition of glutaraldehyde and then incubated at room temperature for $1 \mathrm{~h}$. Cells were post-fixed in a solution containing $1 \% \mathrm{OsO}_{4}$ and $0.8 \%$ potassium ferricyanide, for $1 \mathrm{~h}$, dehydrated in a graded series of acetone, and embedded in Epon resin. Ultrathin sections were stained with uranyl acetate and lead citrate and images were obtained using a Zeiss 900 transmission electron microscope.

\section{Homology modeling}

The PARMODEL web server [25] has been used to model the DNA topoisomerase IB (EC 5.99.1.2) from Leishmania braziliensis in apo form (gene name: LbrM20_V2.3020). The atypical heterodimeric DNA topoisomerase IB from Leishmania is composed of a large subunit containing the phylogenetically conserved "core" domain and a small subunit harboring the $\mathrm{C}$-terminal region with the tyrosine residue common in the active site. This study was carried out on the model of this conserved core that consisted of 430 amino acids. Therefore, we have used the atomic coordinates of topoisomerase IB from Leishmania donovani (PDB access code: 2b9s) [19], which presents $93.25 \%$ identity with the DNA topoisomerase IB (EC 5.99.1.2) from Leishmania braziliensis (LbTOPO). PARMODEL is a parallelized version of the MODELLER web server [26]. All water molecules and DNA atomic coordinates were removed from the topoisomerase IB structure (PDB access code: $2 \mathrm{~b} 9 \mathrm{~s})$ so that the template structure was prepared. The modeling procedure begins from the alignment of the sequence to be modeled (target) with a related threedimensional structure (template). The alignment being considered is usually the input to the program while, on the other hand, the output is a three-dimensional model for the target sequence containing all main-chain and 
side-chain non-hydrogen atoms. In the modeling process, a total of 100 models were generated and the final model was selected based on objective function of the MODELLER.

\section{Molecular docking}

Docking applications can be classified as a function of their search algorithm, which is defined by a set of rules and parameters applied to predict the conformations. When considering the flexibility of the ligand and/or the receptor, docking algorithms can be classified into two major groups: rigid-body and flexible docking. We have applied the flexible docking protocol available in the program MolDock [27], wherein the flexibility of the ligand is simulated. MolDock is an implementation of a heuristic search algorithm that joins together differential evolution and a cavity calculation algorithm. In addition, MolDock evaluates the best poses applying a docking scoring function, which is used to piecewise linear potential (PLP), previously implemented in the program GEMDOCK [28]. As for MolDock, the docking scoring function is extended with an additional term, taking hydrogen bond directionality into account. Furthermore, a re-ranking procedure is also applied in order to augment docking accuracy.

The present docking simulation was based on a previously described protocol applied to Leishmania donovani DNA topoisomerase crystal structure (PDB access code: $2 \mathrm{~b} 9 \mathrm{~s})$. In this protocol the core domain of topoisomerase structure has been used as a target for the docking simulations. A site known to have important residues (Arg-314, Lys-352 and Arg-410) can only be exposed by removing the DNA molecule. The structure of LbTOPO was modeled without DNA or water molecules, as described above.

Lupeol was previously proposed as an important pharmacophore for topoisomerase I inhibition [29]. As regards what has been described, we have employed the lupeol core to access the ZINC database [30] and then build a small-molecule database. A total of 100 molecules were retrieved and used to build this database, which is available for download at http://zinc.docking.org/ [31]. Molecular docking simulations were carried out employing a validated protocol previously described [32].

\section{Statistical analyses}

Results were presented as mean \pm S.D. and were statistically evaluated by Two-Way ANOVA Repeated Measures, followed by the Tukey test at significance level of $\leq 0.05$.

\section{Ethics Statement}

All animals were handled in strict accordance with good animal practice as defined by the relevant national and/ or local animal welfare bodies, and all animal work was approved by the Animal Use Ethics Committee of IPEPATRO (registration number 2008/4).

\section{Results}

\section{Evaluation of macrophage viability}

Murine peritoneal macrophages were treated with the lupane $0.31-10 \mu \mathrm{g} / \mathrm{mL}(6.5-218 \mu \mathrm{M})$ to test the potential toxic effect of this substance on mammalian cells. After $24-96 \mathrm{~h}$ of incubation, cell viability was checked by the MTS cell proliferation assay. Lupane showed no cytotoxic effect at the concentration range of 6.5 $109 \mu \mathrm{M}$. However, at $218 \mu \mathrm{M}$, this compound was seen to be toxic to the macrophages (Fig. 2). Ethanol, used to dilute the compound, showed no cytotoxicity at the concentration used in the test $(1 \% \mathrm{v} / \mathrm{v})$ (data not shown).

\section{Lupane effects on $L$. (L.) amazonensis survival in the host cell}

The effects of the triterpene $3 \beta, 6 \beta, 16 \beta$-triidroxilup-20(29)ene on the viability of $L$. (L.) amazonensis intracellular amastigotes were evaluated during $96 \mathrm{~h}$ of incubation (Fig. 3). The survival index was $100 \%$ for cells of control, $57.9 \%$ for cells treated with lupane $5 \mu \mathrm{g} / \mathrm{mL}(109 \mu \mathrm{M})$, and $47.2 \%$ for cells treated with Glucantime ${ }^{\circ}(546,5 \mu \mathrm{M})$ after $24 \mathrm{~h}$ of treatment. At $48 \mathrm{~h}$, the survival index was 60.3 and $92.3 \%$ for lupane-treated and glucantime-treated cells, respectively, whereas the control was determined to be $100 \%$. There was an increase of $34 \%$ parasite growth within glucantime-treated macrophages, whereas the rate of infection of lupane-treated macrophages remained near $60 \%$. As for the longest time analyzed $(96 \mathrm{~h})$, the survival index was close to $100 \%$ for the control and glucantimetreated cells, and $16.2 \%$ for lupane-treated cells, thereby

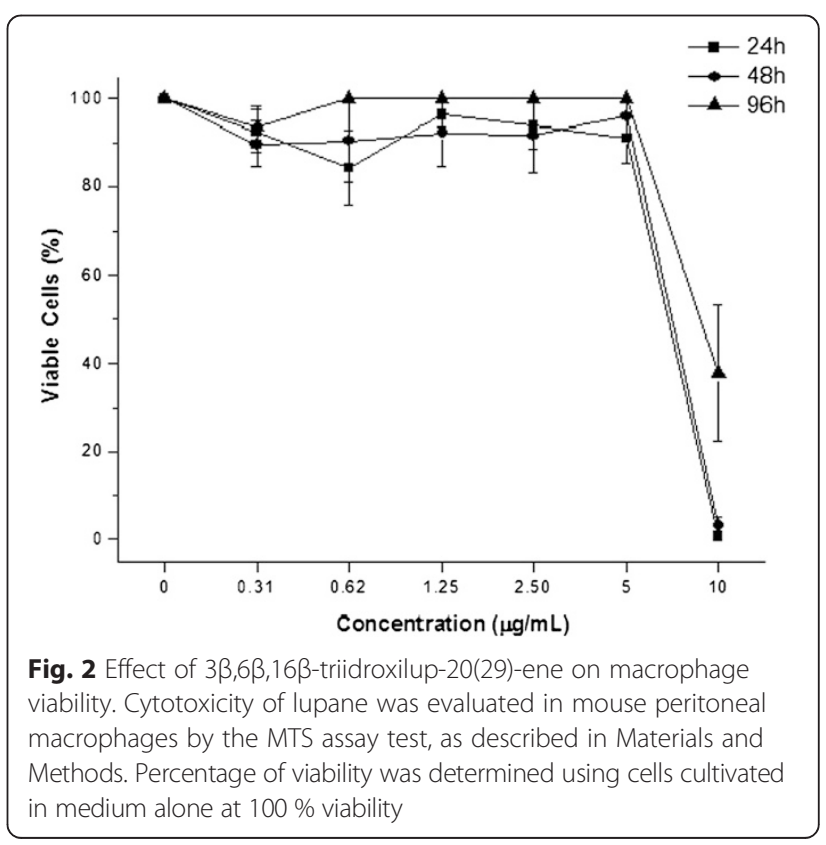



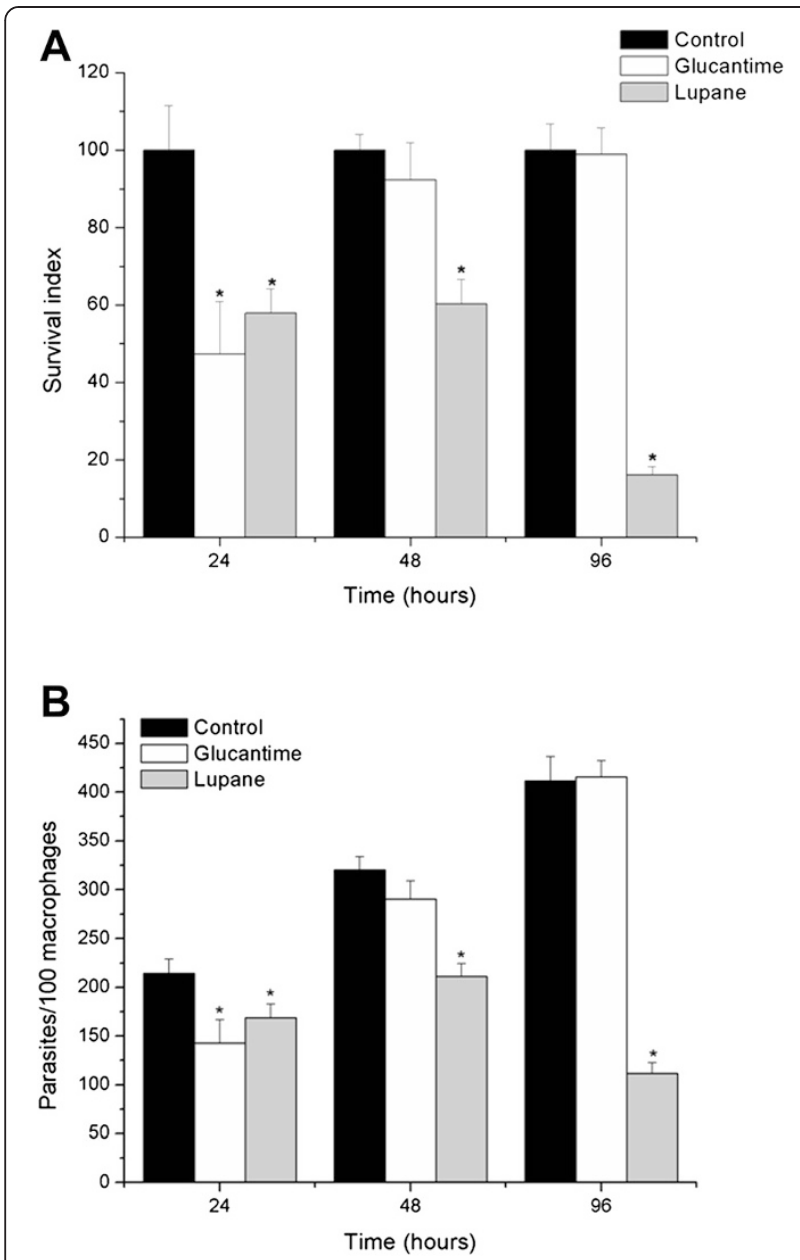

Fig. 3 Effect of lupane on the development of Leishmania (L.) amazonensis within peritoneal macrophage. Infected mouse peritoneal macrophages were treated with $109 \mu \mathrm{M}$ of lupane or $546,5 \mu \mathrm{M}$ of Glucantime ${ }^{\oplus}$ for up to $96 \mathrm{~h}$. The survival index (a) and the number of intracellular amastigotes (b) was determined at the indicated times. Each bar represents the mean \pm standard error of at least three independent experiments, which were performed in duplicate. Statistically significant differences $(p \leq 0.05)$ between treated and non-treated groups are indicated by $\left(^{*}\right)$

reducing the infection rate by $83 \%$ (Fig. 3a). The survival index of macrophages treated with the lupane was significantly lower $(\mathrm{F}=37.4 ; \mathrm{p}<0.0001)$ as compared to the index measured with control macrophages, suggesting that lupane affects the survival of parasites inside macrophages.

In the lupane-treated macrophages, infection was reduced when compared to the control and glucantimetreated macrophages, which showed parasites multiplying progressively (Fig. $3 \mathrm{~b}$ ). At $24 \mathrm{~h}$ post-treatment, the mean number of intracellular amastigotes in Glucantime ${ }^{\circ}$ and lupane-treated macrophages was lower than that in the control cells (33\% and $15 \%$ respectively). Nevertheless, after 96 h, macrophages treated with Glucantime ${ }^{\circ}$ were seen to harbor a number of parasites comparable to the control cells, indicating that this treatment did not interfere with parasite replication. In turn, at this time point, macrophages treated with lupane have harbored a significantly lower number of parasites $(\mathrm{F}=8.6 ; \mathrm{p}=0.0002)$ as compared to control (Fig. 3b). These results indicate that the C. leprosum isolated compound inhibited parasite growth inside the macrophages.

Transmission electron microscopy was used to investigate the effects of lupane on the peritoneal macrophages infected with $L$. (L.) amazonensis. Control-infected cells have exhibited a normal morphology with macrophages containing protozoa (Fig. 4a), and dividing parasites were sometimes observed (Fig. 4b). The ultrastructure of L. (L.) amazonensis amastigotes internalized in macrophages treated with lupane $(109 \mu \mathrm{M})$ for $48 \mathrm{~h}$ was clearly affected, since parasites presented cytoplasmic extraction (Fig. 4c P1 asteristic) and membrane profiles in the region of the flagellar pocket (Fig. 4c, P2 and inset Fig. 4d). The nucleus of treated parasites contained a less condensed chromatin; however the kinetoplast DNA topology was not affected. Lipid vacuoles were noted in the parasite cytosol and parasite membrane shedding was observed (Fig. 4e). Mitochondrial swelling was also observed as well as protozoa visibly destroyed inside vacuoles (Fig. 4c, P3, Fig. 4f).

\section{Molecular docking of lupane and DNA topoisomerase}

The small-molecule database applied in the present work was built using the lupeol core as a source of inspiration. Former studies have identified DNA topoisomerase inhibitory activity in several triterpenes, with micromolar levels of inhibitory potency [29]. These studies strongly suggest that such moiety deserves further investigation as a potential DNA topoisomerase inhibitor. Analyses of 100 docked structures have indicated a score ranging from -15 to -41 , the lowest score being considered the highest-affinity ligand. The analyses of molecular docking simulations (100 docked structures) against the active site of LbTOPO have revealed that lupane was the best ligand, whose lowest score was -41.03 . Fig. $5 \mathrm{a}$ shows this ligand docked to the active site of LbTOPO.

The analysis of the protein-ligand interaction has revealed the participation of intermolecular hydrophobic contacts and hydrogen bonds. All hydroxyl groups present in the lupane participate in intermolecular hydrogen bonds. The main chain carbonyl oxygen and amide nitrogen of Arg 190 participate in hydrogen bonds with a hydroxyl group of lupane. The side chain of Arg 190 makes a strong intramolecular hydrogen bond with the side chain of Asp 353 in the LbTOPO structure, which provides further stability to the structure, working as an anchor for the hydroxyl group of lupane. All the side chains of residues Lys 319, Thr 326 


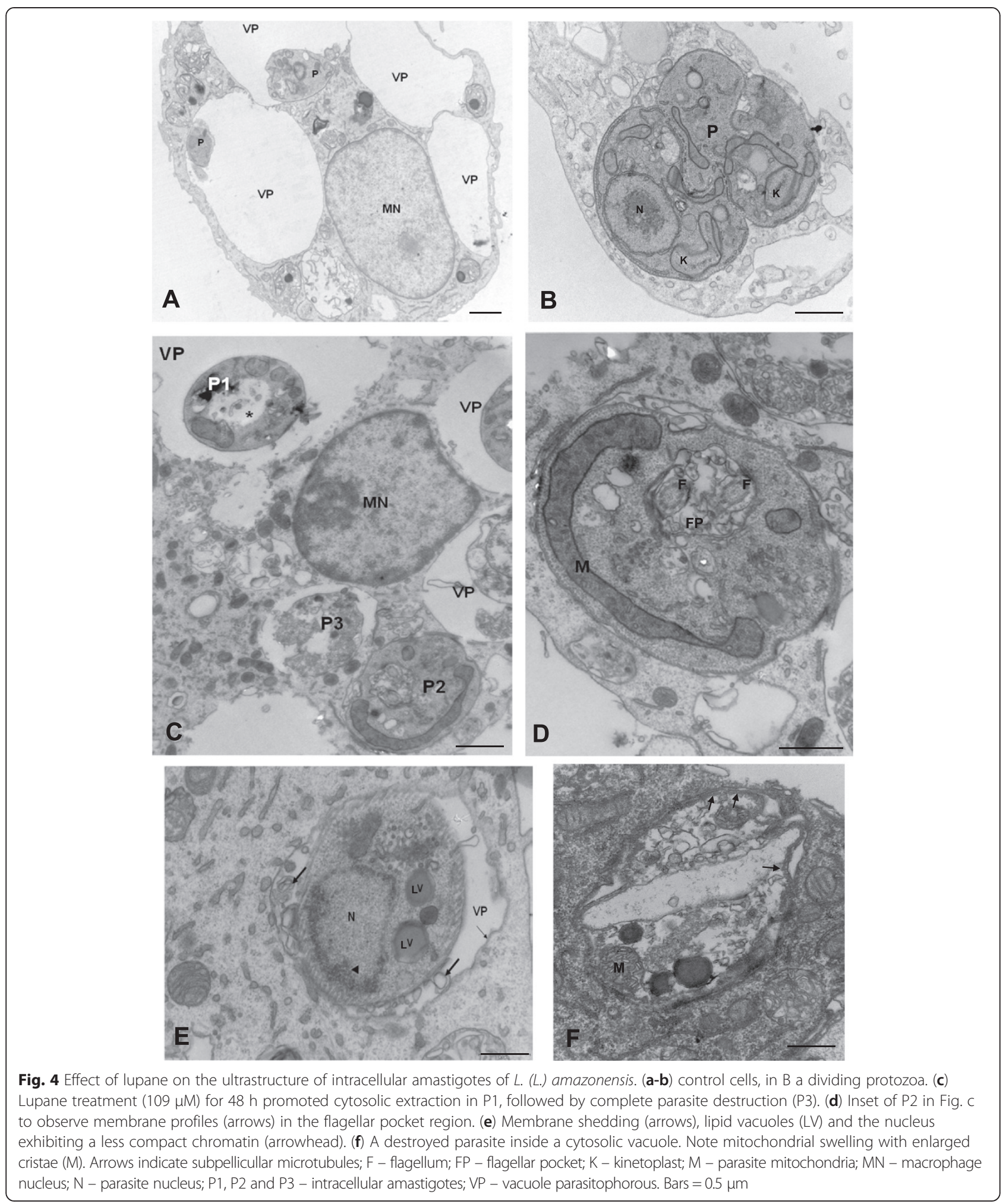

and Lys 352 participate in intermolecular hydrogen bonds; overall, 5 interactions of this type are observed in the LbTOPO-lupane complex. Lys 352 has been previously identified as an important residue of intermolecular interaction in the structure of topoisomerase IB from $L$. (L.) donovani [19]. Likewise, Arg 314 has been proposed as an important spot for intermolecular interaction. In the present structure, the side chain of Arg 314 is about $4 \AA$ 

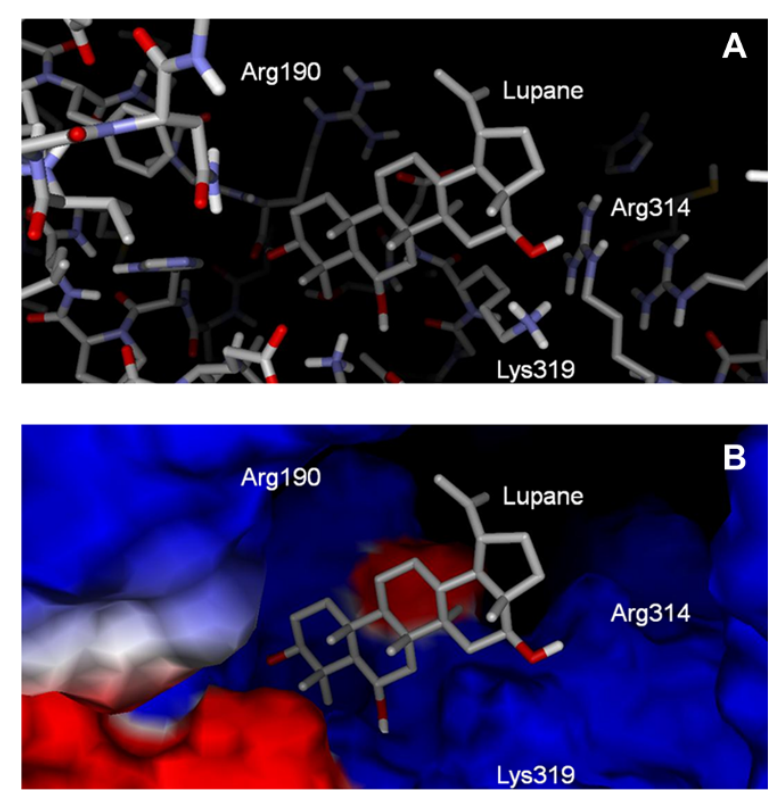

Fig. 5 Docking of lupane at the topoisomerase IB (LbTOPO) active site (a) and eletrostatic molecular surface of active site of topoisomerase IB where lupane is docked (b)

away from the lupane, i.e., the limit for Van der Waals contacts. The analysis of electrostatic molecular surface indicates the presence of a hydrophilic patch in the binding pocket, which favors polar interactions with the hydroxyl groups (Fig. 5b).

\section{Discussion}

The antileishmanial activity of the lupane triterpene isolated from fruits of Combretum leprosum was first described in a previous study, confirming that this plant has a potential antiprotozoal action [14]. Both the crude extract and the isolated lupane have potent toxic activity against L. (L.) amazonensis promastigotes. The present work revealed that the $3 \beta, 6 \beta, 16 \beta$-trihydroxylup-20(29)ene is also effective in eliminating the L. (L.) amazonensis intracellular amastigotes. At the concentration of $109 \mu \mathrm{M}$, no cytotoxicity of lupane has been detected on mouse peritoneal macrophages during the experimental period. However, as expected, concentrations above $218 \mu \mathrm{M}$ showed a significant level of toxicity in the macrophages.

In a related study, a betulinic aldehyde isolated from Doliocarpus dentatus (Aubl.) showed in vitro activity against L. (L.)amazonensis amastigotes, but also showed toxicity against peritoneal macrophages [33]. There is few published data concerning the action of lupanes against protozoa parasites $[34,35]$, and most studies focused the antitumoral activity of these substances [36-39].

Sarek et al. [40] and Kommera et al. [36] demonstrated that minor structural changes on compounds derived from lupane interfere with the in vitro cytotoxic activity against tumor cell lines, suggesting a structureactivity relationship. Our group showed that structural modifications in natural 3 $3,6 \beta, 16 \beta$-trihydroxylup-20(29)ene, such as the presence of acetyl groups at $3 \beta$ and $16 \beta$ abolished its leishmanicidal activity. On the other hand, the replacement of hydroxyl groups by carbonyl groups did not significantly affect its leishmanicidal activity [14]. A recent study from our laboratory compared the lupane leishmanicidal activity against different Leihsmania species and demonstrated that this triterpene also had a potent anti-proliferative effect against the promastigotes of L. braziliensis and L. guyanensis (unpublished results).

The 3 $3,6 \beta, 16 \beta$-trihydroxylup-20(29)-ene concentration adopted in this study was sufficient to reduce the rate of infected macrophages and the number of intracellular amastigotes from $24 \mathrm{~h}$-post treatment onwards. The effect of lupane was time-dependent, reaching a survival index of 16 at 96 h-post treatment. Furthermore, lupane showed a higher inhibitory activity on the growth of leishmania parasites as compared to that of Glucantime ${ }^{\bullet}$.

Maes et al. [6] have analyzed the action of six triterpenes saponins isolated from a Vietnamese plant Maesa balansae Mez. (Myrsinaceae) against $L$. donovani and $L$. infantum. The triterpene saponins from M. balansae inhibit the intracellular growth of L. infantum amastigotes and the subcutaneous administration of $0.4 \mathrm{mg} / \mathrm{kg}$ of the substance in BALB/c mice infected with L. donovani was able to reduce the parasite load by $95 \%$. Additionally, the triterpene saponin named Maesabalide III had the most potent antileishmanicidal activity in vivo towards $L$. donovani-infected hamsters, leading to a $99.8 \%$ reduction of the parasite load after a seven-day treatment [41].

Glucantime ${ }^{\bullet}$, which is one of the drugs currently used in the treatment of leishmaniasis, was unable to reduce infection over the time analysed. Infected cells treated with Glucantime ${ }^{\circledast}$ showed a survival index of 47.2 at $24 \mathrm{~h}$, but this index was seen to increase to 98.8 at $96 \mathrm{~h}$. Since the 40s', pentavalent antimonials are the drugs of choice for the treatment of leishmaniasis; however, the mechanism of action of two of them - meglumine antimoniate (Glucantime ${ }^{\odot}$ ) and sodium stibogluconate - is not well known. Several studies suggest that pentavalent antimony may be a pro-drug and that it can be converted into trivalent antimony inside the infected cell possibly interfering in the process of glycolysis of the parasite. Moreover, it could affect enzyme inhibition and thereby lead to the depletion of intracellular ATP levels $[42,43]$. Unfortunately, these drugs cause severe side effects and the treatment is usually extensive.

In this work, the parasite ultrastructure was affected by the treatment with lupane, since cells exhibited loss 
of cytosolic content, which culminated in cell lysis. The nucleus of the treated leishmania presented a less compact chromatin and it was observed mitochondrial swelling as previously reported after the use of topoisomerase I inhibitors in Trypanosoma cruzi [44]. Zuma et al. [44] showed that Camptothecin and rebeccamycin, eukaryotic topoisomerase I inhibitors, were effective in arrest of $T$. cruzi replication and the ultrastructural alterations, such as the unpacking of nuclear heterochromatin and mitochondrial swelling were observed.

Chowdhury et al. [45] showed that dihydrobetulinic acid - a derivative of betulinic acid - has antileishmanial activity against both $L$. donovani promastigotes and amastigotes forms, and that it inhibits DNA topoisomerases I and II. This pentacyclic triterpenoid causes damage in nuclear DNA and induces apoptosis in $L$. donovani parasites. The same authors have recently demonstrated that three synthetic derivatives of betulin (disuccinylbetulin, diglutaryldihydrobetulin, and disuccinyldihydrobetulin) reduced replication of the intracellular $L$. donovani amastigotes, in addition to inhibiting the relaxation activity of the enzyme type IB topoisomerase [Leishmania donovani topoisomerase I (LdTOP1LS)] of the parasite [46].

The analysis of the intermolecular interaction between $3 \beta, 6 \beta, 16 \beta$-trihydroxylup-20(29)-ene and LbTOPO indicates a perfect coupling and a strong binding affinity. The strong antileshmanial activity interfering with amastigote survival, and the high virtual affinity binding with LbTPOPO suggest that the $3 \beta, 6 \beta, 16 \beta$-trihydroxylup20(29)-ene may be a potential inhibitor of $L$. (L.) amazonensis topoisomerase IB. The in silico data is necessary to confirm this inhibiton, but results indicate that the used bioinformatic analyses were able to identify potential new antileishmanial drugs.

Type IB topoisomerases are enzymes essential to cell life which form a covalent bond with the 3' end of broken DNA strands. Leishmania type I DNA topoisomerase differ from their homologues in other eukaryotic cells. The DNA topoisomerases I from mammalian hosts are monomeric enzymes, whereas the trypanosomatid type I DNA topoisomerases are heterodimeric [47, 48]. Moreover, this enzyme has a dual localization in trypanosomatids: in the nucleus, associated with genomic DNA, and in the kinetoplast, associated with kDNA $[49,50]$. These differences make such enzyme a potential target for chemotherapeutic intervention in diseases caused by trypanosomatids parasites.

A big step was taken forward in the development of drugs over the last years, allowing for the treatment of a broad spectrum of pathologies. Unfortunately, diseases caused by protozoan parasites, such as trypanosomes, leishmania and plasmodia are not included in research and development programs from the pharmaceutical sector [51, 52], resulting in a challenging scenario for the development of new drugs in face of these orphan diseases.

\section{Conclusion}

Finally, the results of this study have revealed that a natural triterpene, a lupane isolated from C. leprosum, has antileishmanial activity against $L$. (L.) amazonensis intracellular amastigotes and, by bioinformatic analysis, interacts with type IB parasite DNA topoisomerase. This compound represents a new source of molecules for the development of novel antiprotozoal agent and may be a potential candidate for the treatment of leishmaniasis.

\section{Competing interests}

The authors declare no conflict of interests.

\section{Authors' contributions}

CBGT carried out the biological assays, data analyses and helped in manuscript writing and editing. LSM and VAF provided the plant material and helped in biological assays. WFAJ participated in the molecular docking analyses. MCMM carried out the transmission electron microscopy analyses. AAS participated in the design of the study and performed the statistical analysis. LHPS and RGS helped to draft the manuscript. ISJ conceived of the study and participated in its design, coordination and data analyses and drafted the manuscript. All authors read and approved the final manuscript.

\section{Acknowledgements}

This work was supported by CNPQ (National Council for Scientific and Technological Development) and FAPERJ.

\section{Author details}

'Malaria and Leishmaniasis Bioassays platform, Oswaldo Cruz Foundation (Fiocruz Rondônia), Porto Velho, Rondônia, Brazil. ${ }^{2}$ Center of Studies for Biomolecules Applied to Health (CEBio), Oswaldo Cruz Foundation (Fiocruz Rondônia), Porto Velho, Rondônia, Brazil. '²aboratory of Insect Bioecology, Universidade Federal de Rondônia (UNIR), Porto Velho, Rondônia, Brazil. ${ }^{4}$ Laboratory of Medical Entomology, Oswaldo Cruz Foundation (Fiocruz Rondônia), Porto Velho, Rondônia, Brazil. ${ }^{5}$ Research Laboratory of Chemistry of Natural Products, Universidade Federal de Rondônia (UNIR), Porto Velho, Rondônia, Brazil. 'Structural Biochemistry Laboratory, PUC, Rio Grande do Sul, Porto Alegre, Brazil. 7 Laboratory of Molecular Epidemiology, Research Institute for Tropical Diseases in Rondônia (IPEPATRO), Porto Velho, Rondônia, Brazil. ${ }^{8}$ Laboratory of Cellular Ultrastructure Hertha Meyer, Institute of Biophysics, Universidade Federal do Rio de Janeiro (UFRJ), Rio de Janeiro, Brazil. ${ }^{9}$ Department of Biological Sciences, Universidade Estadual de Santa Cruz (UESC), Ilheús, Bahia, Brazil.

Received: 16 June 2014 Accepted: 20 May 2015

Published online: 06 June 2015

\section{References}

1. Naderer T, McConville MJ. Intracellular growth and pathogenesis of Leishmania parasites. Essays Biochem. 2011;51:81-95.

2. Singh N, Kumar M, Singh RK. Leishmaniasis: current status of available drugs and new potential drug targets. Asian Pac J Trop Med. 2012;5:485-97.

3. Machado PR, Penna G. Miltefosine and cutaneous leishmaniasis. Curr Opin Infect Dis. 2012;25:141-4.

4. Zhai L, Chen M, Blom J, Theander TG, Christensen SB, Kharazmi A. The antileishmanial activity of novel oxygenated chalcones and their mechanism of action. J Antimicrob Chemother. 1999:43:793-803.

5. Grandic SR, Fourneau C, Laurens A, Bories C, Hocquemiller R, Loiseau PM. In vitro antileishmanial activity of acetogenins from Annonaceae. Biomed Pharmacother. 2004;58:388-92. 
6. Maes $L$, Berghe DV, Germonprez N, Quirijnem L, Cos P. In vitro and in vivo activities of a triterpenoid saponin extract (PX-6518) from the plant Maesabalansae against visceral Leishmania species. Antimicrob Agents Chemother. 2004;48:130-6.

7. Silva FMA, Koolen HHF, Lima JPS, Santos DMF, Silva-Jardim I, Souza ADL, et al. Leishmanicidal activity of fractions rich in aporphine alkaloids from Amazonian Unonopsis species. Rev Bras Farmacogn. 2012;22:1368-71.

8. Paes-Goncalves HP, Facundo VA, Santos DMF, Silva AGC, Ballico LJ, Lima DKS, et al. The leishmanicidal activity of a cyclopentenedione derivative isolated from the roots of a native Amazonian pepper (Piper carniconnectivum C. DC, Piperaceae). Rev Bras Farmacogn. 2012;22:1018-23.

9. Santos AO, Izumi E, Ueda-Nakamura T, Dias-Filho BP, Veiga-Júnior VF, Nakamura CV. Antileishmanial activity of diterpeneacids in copaibaoil. Mem Inst Oswaldo Cruz. 2013;108:59-64.

10. Croft SL, Karin S, Yardley V. Current scenario of drug development for leishmaniasis. Indian J Med Res. 2006;123:399-410.

11. Facundo VA, Andrade CHS, Silveira ER, Braz-Filho R, Hufford C. Triterpenes and flavonoids from Combretum leprosum. Phytochemistry. 1993;32:411-5.

12. Pietrovski EF, Rosa KA, Facundo VA, Rios K, Marques MC, Santos AR. Antinociceptive properties of the ethanolic extract and of the triterpene 3 beta,6beta, 16beta-trihidroxilup-20(29)-ene obtained from the flowers of Combretum leprosum in mice. Pharmacol Biochem Behav. 2006;83:90-9.

13. Facundo VA, Rios KA, Medeiros CM, Militão JSLT, Miranda ALP, Epifânio RA et al. Arjunolic acid in the ethanolic extract of Combretum leprosum root and its use as a potential multi-functional phytomedicine and drug for neurodegenerative disorders: anti-inflammatory and anticholinesterasic activities. J Braz Chem Soc. 2005;16:1309-12.

14. Teles CBG, Moreira LS, Silva AA, Facundo VA, Zuliani JP, Stábeli RG, et al. Activity of the Lupane isolated from Combretum leprosum against Leishmania amazonensis promastigotes. J Braz Chem Soc. 2011;22:936-42

15. Silveira FT, Lainson R, Corbett CEP. Clinical and immunopathological spectrum of American cutaneous leishmaniasis with special reference to the disease in Amazonian Brazil. A Review Mem Inst Oswaldo Cruz. 2004;99:239-51.

16. Barral A, Pedral Sampaio D, Grimaldi Jr G, Momem HMC, Mahon-Pratt D, Jesus A, et al. Leishmaniasis in Bahia, Brazil: evidence that Leishmania amazonensis produces a wide spectrum of clinical disease. Am J Trop Med Hyg. 1991;44:536-46.

17. Morrison B, Mendoza I, Delgado D, Reyes Jaimes O, Aranzazu N, Paniz-Mondolfi AE. Diffuse (anergic) cutaneou leishmaniasis responding to amphotericin B. Clin Exp Dermatol. 2009:35:116-9.

18. Zerpa O, Ulrich M, Blanco B, Polegre M, Ávila A, Matos N, et al. Diffuse cutaneous leishmaniasis responds to miltefosine but then relapses. Brit J Dermatol. 2007;156:1328-35.

19. Davies DR, Mushtaq A, Interthal H, Champoux JJ, Hol WG. The structure of the transition state of the heterodimeric topoisomerase I of Leishmania donovani as a vanadate complex with nicked DNA. J Mol Biol. 2006:357:1202-10.

20. Bodley AL, Shapiro TA. Molecular and cytotoxic effects of camptothecin, a topoisomerase I inhibitor, on trypanosomes and Leishmania. Proc Natl Acad Sci U S A. 1995;92:3726-30

21. Balaña-Fouce R, Alvarez-Velilla R, Fernández-Prada C, García-Estrada C, Reguera RM. Trypanosomatids topoisomerase re-visited. New structura findings and role in drug discovery. Int J Parasitol Drugs Drug Resist. 2014:4:326-37.

22. Motta MCM. Kinetoplast as a potential chemotherapy target of trypanosomatids. Curr Pharm Des. 2008;14:847-54.

23. Silva-Jardim I, Horta MF, Ramalho-Pinto FJ. The Leishmania chagasi proteasome: role in promastigotes growth and amastigotes survival within murine macrophages. Acta Trop. 2004;91:121-30.

24. Giaimis J, Lombard Y, Makaya-Kumba M, Fonteneau P, Poindron P. A new and simple method for studying the binding and ingestion steps in the phagocytosis of yeasts. J Immunol Methods. 1992;154:185-93.

25. Uchoa HB, Jorge GE, Da Silveira NJF, Camera JC, Canduri F, De Azevedo WF. Parmodel: a web server for automated comparative modeling of proteins. Biochem Biophys Res Commun. 2004;325:1481-6.

26. Sali A, Blundell TL. Comparative protein modelling by satisfaction of spatial restraints. J Mol Biol. 1993;234:779-815.
27. Thomsen R, Christensen MH. MolDock: a new technique for high-accuracy molecular docking. J Med Chem. 2006;49:3315-21.

28. Yang JM, Chen CC. GEMDOCK: a generic evolutionary method for molecular docking. Proteins. 2004:55:288-304.

29. Wada S, lida A, Tanaka R. Screening of triterpenoids isolated from Phyllanthus flexuosus for DNA topoisomerase inhibitory activity. J Nat Prod. 2001;64:1545-7.

30. Irwin JJ, Shoichet BK. ZINC-a free database of commercially available compounds for virtual screening. J Chem Inf Model. 2005:45:177-82.

31. Timmers LFS, Pauli I, Caceres RA, De Azevedo Jr WF. Drug-Binding Databases. Curr Drug Targets. 2008;9:1092-9.

32. Misra P, Khaliq T, Dixit A, SenGupta S, Samant M, Kumari S, et al. Antileishmanial activity mediated by apoptosis and structure-based target study of peganine hydrochloride dihydrate: an approach for rational drug design. J Antimicrob Chemother. 2008;62:998-1002.

33. Sauvain M, Kunesch N, Poisson J, Gantier J-C, Gayral P, Dedet J-P. Isolation of leishmanicidal triterpenes and lignans from Amazoniam liana Doliocarpus dentatus (Dellineaceae). Phytother Res. 1996;10:1-4.

34. Gnoatto SC, DallaVechia L, Lencina CL, Dassonville-Klimpt A, Da Nascimento S, Mossalayi D, et al. Synthesis and preliminary evaluation of newursolic and oleanolic acids derivatives as antileishmanial agents. J Enzyme Inhib Med Chem. 2008;23:604-10.

35. Silva-Filho AA, Resende DO, Fukui MJ, Santos FF, Pauletti PM, Cunha WR, et al. In vitro antileishmanial, antiplasmodial and cytotoxic activities of phenolics and triterpenoids from Baccharis dracunculifolia D. C. (Asteraceae). Fitoterapia. 2009:80:478-82.

36. Kommera H, Kaluderović GN, Kalbitz J, Dräger B, Paschke R. Small structural changes of pentacyclic lupane type triterpenoid derivatives lead to significant differences in their anticancer properties. Eur J Med Chem. 2010;45:3346-53.

37. Lee DY, Seo KH, Lee DS, Kim YC, Chung IS, Kim GW, et al. Bioactive 3,4-seco-Triterpenoids from the Fruits of Acanthopanax sessiliflorus. J Nat Prod. 2012;75:1138-44.

38. Laszczyk MN. Pentacyclic triterpenes of the lupane, oleanane and ursane group as tools in cancer therapy. Planta Med. 2009;75:1549-60.

39. Pisha E, Chai H, Lee IS, Chagwedera TE, Farnsworth NR, Cordell GA, et al. Discovery of betulinic acid as a selective inhibitor of human melanoma that functions by induction of apoptosis. Nat Med. 1995;1:1046-51.

40. Sarek J, Klinot J, Dzubák P, Klinotová E, Nosková V, Krecek V, et al. New lupane derived compounds with pro-apoptotic activity in cancer cells: synthesis and structure-activity relationships. J Med Chem. 2003;46:5402-15.

41. Maes L, Germonprez N, Quirignen L, Puyvelde LV, Cos P, Berghe DV. Comparative activities of the triterpenesaponin Maesabalide III and Liposomal amphotericin B (AmBisome) against Leishmania donovani in Hamsters. Antimicrob Agents Chemother. 2004;48:2056-60.

42. Berman JD, Waddell D, Hanson BD. Biochemical Mechanisms of the Antileishmanial Activity- of Sodium Stibogluconate. Antimicrob Agents Chemother. 1985;27:916-20.

43. Frézard F, Martins PS, Barbosa MC, Pimenta AM, Ferreira WA, de Melo JE, et al. New insights into the chemical structure and composition of the pentavalent antimonial drugs, meglumine antimonate and sodium stibogluconate. J Inorg Biochem. 2008;102:656-65.

44. Zuma AA, Cavalcanti DP, Maia MC, De Souza W, Motta MCM. Effect of topoisomerase inhibitors and DNA-binding drugs on the cell proliferation and ultrastructure of Trypanosoma cruzi. Int J Antimicrob Agents. 2011;37:449-56

45. Chowdhury AR, Mandal S, Goswami A, Ghosh M, Mandal L, Chakraborty D, et al. Dihydrobetulinic acid induces apoptosis in Leishmania donovani by targeting DNA topoisomerase I and II: implications in antileishmanial therapy. Mol Med. 2003;9:26-36.

46. Chowdhury S, Mukherjee T, Sengupta S, Chowdhury SR, Mukhopadhyay S, Majumder HK. Novel betulin derivatives as antileishmanial agents with mode of action targeting type IB DNA topoisomerase. Mol Pharmacol. 2011;80:694-703.

47. Villa H, Otero Marcos AR, Reguera RM, Balaña-Fouce R, García-Estrada C, Pérez-Pertejo $Y$, et al. A novel active DNA topoisomerase I in Leishmania donovani. J Biol Chem. 2003;278:3521-6.

48. Reguera RM, Redondo CM, Gutierrez de Prado R, Pérez-Pertejo Y, Balaña-Fouce R. DNA topoisomerase I fromparasitic protozoa: a potential target for chemotherapy. Biochim Biophys Acta. 2006;1759:117-31. 
49. Bodley AL, Chakraborty AK, Xie S, Burri C, Shapiro TA. An unusual type IB topoisomerase from African trypanosomes. Proc Natl Acad Sci U S A. 2003;100:7539-44.

50. Das BB, Sen N, Ganguly A, Majumder HK. Reconstitution and functional characterization of the unusual bi-subunit type I DNA topoisomerase from Leishmania donovani. FEBS Lett. 2004:565:81-8.

51. De Azevedo Jr WF. Targets for Development of Drugs Against Orphan Diseases. Curr Drug Targets. 2007:8:387.

52. De Azevedo Jr WF, Soares MBP. Selection of targets for drug development against protozoan parasites. Curr Drug Targets. 2009;10:193-201.

\section{Submit your next manuscript to BioMed Central} and take full advantage of:

- Convenient online submission

- Thorough peer review

- No space constraints or color figure charges

- Immediate publication on acceptance

- Inclusion in PubMed, CAS, Scopus and Google Scholar

- Research which is freely available for redistribution 